\title{
O PROCESSO TÉCNICO-CRIATIVO NA EXPERIÊNCIA DE TRADUÇÃO DE LITERATURA INFANTIL: ENTRE PALAVRAS E SABORES
}

\author{
THE TECHNICAL-CREATIVE PROCESS IN THE TRANSLATION OF \\ CHILDREN'S LITERATURE: BETWEEN WORDS AND FLAVORS
}

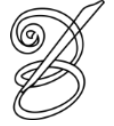 \\ Daniela BUNN* \\ Universidade Federal de Santa Catarina, Brasil \\ Sergio ROMANELLI ${ }^{* *}$ \\ Universidade Federal de Santa Catarina, Brasil \\ Bolsista de Produtividade em Pesquisa do CNPq - Nível 2 \\ Valeria ISOPPO**** \\ Tradutora Juramentada do Estado de Santa Catarina, Brasil
}

Resumo: Estas reflexões visam socializar experiências no campo da tradução de literatura infantojuvenil, da língua portuguesa para a italiana, a partir de um projeto da Editora Cuca Fresca. Foram publicados, em 2011, dois livros, Mariolino e Luigino e La casa della nonnina è troppo carina, além do exercício de tradução de Minha tia faz doce no tacho. Os livros apresentam cenas da vida quotidiana familiar e suas traduções oferecem um material diferenciado para difusão da língua italiana. Avaliar as dificuldades, a importância e as peculiaridades da tradução de LIJ, em relação aos elementos textuais e visuais, é também objetivo dessa discussão. Traduções e discussões realizadas, mesclando saber e sabor. Sabor tanto das histórias como do próprio processo técnico, criativo e recreativo.

Palavras-chave: Estudos da Tradução. Literatura Infantil. Experiências.

Abstract: These reflections, which resulted from a project developed by Cuca Fresca publisher, aim at socializing some experiences in the field of Children's Literature Translation, from Portuguese to Italian. Two books were translated and published in 2011, Mariolino e Luigino and La casa della nonnina è troppo carina. The books present scenes of the everyday family life and their translations seem to offer an interesting and differentiated material that may contribute to the diffusion of Italian language. This discussion also aims at evaluating the difficulties, the importance and the peculiarities of Children's Literature Translation in relation to textual and visual elements. The reflections and translations developed in this work, are a mixture of knowledge and pleasure. Pleasure with the stories and with the technical-creative and recreative process.

Keywords: Translation Studies. Children's Literature. Experiences.

RECEBIDO EM: 14 de fevereiro de 2019

ACEITO EM: 4 de maio de 2019

PUBLICADO EM: julho 2019 


\section{Introdução}

$\mathrm{U}$

ma troca de ideias, um convite, uma falta. Interrogada sobre a carência de material literário em língua italiana acessível aos leitores brasileiros e, principalmente, diante de uma grande demanda no Estado de Santa Catarina, a editora Cuca Fresca lançou um plano de tradução. Com o intuito de disponibilizar um material literário para falantes, alunos, estudiosos, estagiários e professores de italiano, o projeto tomou forma e a equipe de tradutores foi montada. O que relatamos a seguir são algumas estratégias e dificuldades encontradas no percurso da tradução de três livros infantis, dois deles publicados. Os livros, Maricota e Cocota (2009), de Marta Martins, Casa de vó é gostoso que só! (2010), de Magali Queiroz e Minha tia faz doce no tacho (2008), de Adriano Messias, que têm como língua de partida o português brasileiro, foram traduzidos ao italiano primeiramente para difusão em território nacional, o que trouxe ao processo técnico-criativo um grande diferencial: o leitor de partida era também o leitor de chegada. Avaliar as dificuldades, a importância e as peculiaridades da tradução de Literatura Infantojuvenil (doravante LIJ), em relação aos elementos textuais e visuais, é também objetivo dessa discussão, a fim de contribuir para o

74 entendimento do processo de tradução. Apresentamos algumas opções encontradas pelos tradutores que demonstram o complexo processo de reconstrução do texto a partir de algumas peculiaridades que elencaremos a seguir.

Segundo Umberto Eco (2003), o tradutor deve ter a sensibilidade para negociar possibilidades pertinentes tanto relacionadas ao contexto como ao objetivo da tradução e, dessa forma, se aproximar do público-alvo. Com este intuito, começamos explorando algumas dessas possibilidades, negociadas, primeiramente, a três vozes, momentos nos quais a tradução literal não supriu os objetivos referentes seja ao texto, seja à relação texto-imagem. Como o leitor para esses textos quer-se amplo, temos também níveis diferentes de leitura: da criança que lerá procurando identificar aspectos lúdicos ao adulto ou estudioso que lerá observando a estruturação da língua italiana. Considerando esse aspecto, levamos em conta na tradução também o objetivo de ampliação do vocabulário por parte do leitor-aprendiz.

Os livros apresentam cenas da vida quotidiana familiar e suas traduções oferecem um material diferenciado para difusão da língua italiana. Como destaca Renata Mundt (2008, p. 2), há várias instâncias interferentes no processo de tradução de literatura infantojuvenil, que não se limitam apenas ao tradutor, mas à visão que temos da criança/leitor da cultura de partida, da cultura de chegada e dos interesses mercadológicos. Mundt, com vasta experiência no campo da tradução do alemão para o português, elenca algumas formas de adaptação possíveis no 
campo da literatura infantil:

[...] quando se trata apenas de um termo ou expressão, a utilização do termo acrescentando uma explicação no próprio texto; a substituição do termo/ expressão por um conteúdo explicativo (tradução explicativa); a omissão do termo/expressão, o que pode ser problemático e obrigar à reformulação do conteúdo no qual ele está contido; a utilização de uma explicação externa ao texto; o uso de um termo equivalente; o uso de um termo semelhante; a simplificação, ou seja, o uso de um conceito mais geral no lugar de um específico; a localização ou domesticação, processo em que todo o conteúdo é aproximado do ambiente cultural do leitor da tradução. (MUNDT, 2008, p. 1).

\section{0 processo técnico-criativo: palavras iniciais}

Várias vezes nos indagamos sobre a especificidade de nosso futuro leitor: público infantojuvenil brasileiro aprendiz de italiano, comunidade de ascendência italiana no estado de Santa Catarina e no país, aprendizes adultos de nível inicial de italiano que conhecem pouco ou muito da Itália contemporânea. Como afirmou Rosenweig (1994, p. 47), traduzir é servir a dois amos, o estrangeiro em sua obra e o leitor em seu desejo de apropriação. Embora tivéssemos a mudança de língua (português-italiano), tínhamos a necessidade de manter o registro cultural do material de base ao aproximá-lo do contexto brasileiro desta vasta gama de leitores.

Tivemos muitos pontos de tensão nesse processo, como, por exemplo, no momento de traduzir pratos específicos da culinária mineira, conforme veremos mais adiante. Por outro lado, os três tradutores tinham a sorte de contar com uma experiência de vários anos de contato com alunos de língua e literatura italiana que seriam prováveis leitores iniciais dos livros. Essa experiência possibilitava escolhas tradutórias já embutidas de uma projeção didática - o que seguia também o objetivo editorial proposto. Assim,

\footnotetext{
O ato de traduzir constitui um processo criativo e esse processo criativo, como já Levý afirmou em 1965, é parte de um processo comunicativo em que o tradutor opta, decide, escolhe entre uma série de possibilidades alternativas. A questão é saber não somente como, mas por que o tradutor faz determinadas opções descartando umas e aceitando outras; quais os elementos que interferem neste processo de problemsolving? Como se pode acompanhar esse processo sem registros, sem marcas, sem índices, se todo esse complexo percurso é apagado ao ser editada a tradução? A tradução editada é somente uma etapa desse percurso criativo comparável a um xadrez. (ROMANELLI, 2010, p. 2).
}

Em nosso jogo de xadrez, de fato, muitas foram as jogadas, pensadas e repensadas. E essas marcas, embora não apareçam nos textos finais, ficaram guardadas em nossas gavetas. Por vezes voltamos ao tabuleiro dos rastros para refletir sobre as escolhas feitas e percebemos, nesse olhar retrospectivo, que seguimos uma postura mais cognitivista para a divisão do texto 
em unidades de tradução. A unidade tradutória (UT) não é nem a menor unidade de um texto, nem ele todo. Pode mudar de tamanho e sua definição depende de nossa bagagem pessoal e pode ser reformulada sintática ou semanticamente em função dos objetivos (ALVES, 2010, p. 29-38).

A escolha de nossas unidades tradutórias foi flexível, personalizada, feita de acordo não só com nossa experiência com o ensino de literatura e de italiano como língua estrangeira (LE), mas também com base em nossas memórias de crianças crescidas em um contexto ítalobrasileiro. Considerando o tipo de livro trabalhado, nossa unidade tradutória consistia na cena que se colocava para o leitor e nas palavras se circunscreviam no contexto da ilustração: quando a imagem ocupava somente uma página, era este o foco; quando se estendia pelas duas páginas do livro aberto, o texto ali exposto não teria como não se relacionar.

O processo de tradução aconteceu em etapas: uma tradução inicial por um tradutor, uma leitura dessa tradução pelo segundo tradutor, seguida pela revisão final do terceiro tradutor. Fizemos isso em forma de rodízio com os três livros. A quarta etapa foi uma roda de discussão e revisão final onde pudemos discutir o emprego de cada frase, cada expressão, e fazer as 76 escolhas lexicais finais, dos elementos culturais pertinentes, dos nomes próprios, das rimas, da relação com as ilustrações e o gênero das palavras e dos alimentos. Vejamos alguns exemplos.

\section{Nomes próprios, gênero, nonsense : a relação com a ilustração}

A frase de Calvino (1990, p. 16), "revire o livro entre as mãos, percorra o texto da contracapa, das orelhas [...]. É certo que este passeio ao redor do livro - ler o que está fora antes de ler o que está dentro - também faz parte do prazer da novidade", bem cabe ao nosso contexto. O livro infantil deve ser explorado de todas as maneiras, pois pode trazer surpresas em seus meandros, como pequenas marcas intertextuais que prendem a atenção dos leitoresexploradores mais atentos. Como falamos anteriormente, um desses elementos é a ilustração.

Com um olhar diferenciado, a experiência literária pode ser intensificada duplamente: pelo texto e pela imagem. O crítico e ilustrador Luis Camargo (2003) retoma em seu texto, como modelo de análise para as ilustrações, as funções da linguagem de Roman Jakobson (2005). Das onze categorias resenhadas e destacadas por Camargo, as imagens nos livros traduzidos apenas não apresentavam as funções simbólica (propondo metáforas) ou metalinguística (que fala sobre a sua ou outra linguagem), o que por um lado facilitava a tradução. Também as funções conativa (que sugere/influencia/persuade) e fática (que dá ênfase com texturas, por exemplo) não estavam presentes. Dentre as categorias utilizadas pelo autor, 
as que mais frequentemente apareceram foram: a forma representativa, imitando a aparência dos objetos, e a forma descritiva, detalhando-os (na maioria das imagens em Casa de vó é gostoso que só! e Maricota e Cocota); algumas vezes a forma narrativa, marcando uma passagem de tempo (com a imagem da lua ou do nascer do sol), e a forma expressiva, ressaltando sentimentos e valores; e, muitas vezes, a forma lúdica, com humor.

Todas essas funções tiveram que ser observadas em nossas unidades tradutórias para que articulássemos texto e imagem. Além das questões concernentes às particularidades das línguas envolvidas - inserção de mais artigos, substituição de formas impessoais como o infinitivo e o gerúndio por verbos conjugados, maior utilização dos pronomes em geral tivemos que perceber se com a mudança de gênero dos substantivos, que ocorre frequentemente de uma língua para outra, corríamos o risco de criar contradição entre texto e ilustração. No caso do livro Maricota e Cocota, no qual os nomes próprios referem-se a duas escovas de dente, uma azul e outra vermelha, optamos por chamá-las de Mariolino e Luigino, pois escova de dente traduz-se como spazzolino, uma mudança de gênero (feminino para masculino) que não entrou em divergência com a ilustração.

Outro exemplo é o caso da palavra geladeira que, em italiano, atende pelo significante frigorifero, masculino. No livro Minha tia faz doce no tacho, o ilustrador optou por uma geladeira azul, criando um efeito nonsense com o nome "Rosinha", proposto pelo autor. Em língua italiana, para manter essa contradição divertida entre cor significante e cor significada, chamamos o frigorifero de Rosetto.

Dessa forma, buscamos manter na tradução esse choque entre o código visual e o escrito e ficamos com o seguinte resultado:

Na copa vive Rosinha, a geladeira azul onde tia Nice guarda o queijo que se come com o doce. Congela quando quer e, se o motor está animado, sai valsando pela cozinha. (MESSIAS, 2012, p. 12-13)

Tradução:

In cucina abita Rosetto, il frigorifero azzurro nel quale zia Nice tiene il formaggio che si mangia con una fetta di quel dolce al taglio. Il frigo funziona quando vuole e se il suo motore è di buon umore gira per la cucina ballando un valzer.

Muitas vezes, nos livros infantis, o conjunto texto/ilustração gera efeitos cômicos sutis, de difícil tradução. Isso porque a comicidade, como dissera Bergson (2001, p. 05), é um fato 
social: "Muitos efeitos cômicos são intraduzíveis de uma língua para outra" por serem "relativos aos costumes e às ideias de uma sociedade em particular".

Como na produção do texto nonsense, o autor joga simultaneamente com a multiplicidade e a ausência de significados, na empreitada do tradutor, que encara composições contraditórias de textos e imagens, também entra a capacidade de brincar com as regras da língua, da lógica, da prosódia e da representação (ISOPPO, 2004, p. 79). Essa mesma competência tradutória deve estar presente na recriação das rimas, como veremos a seguir.

\section{Rimas, literalidade, reescritura}

Ao traduzir textos com rimas, é pertinente que se mantenha a estilística, como no título de um dos livros traduzidos: “Casa de vó é gostoso que só!”. Tínhamos algumas opções:

(1) La casa della nonna è troppo bella!; (2) La casa della nonna è troppo buona!; (3) La casa della nonnina è troppo carina!

Esta última foi a opção escolhida porque mantinha a rima. Embora a segunda opção também rimasse, o adjetivo "buona", diferente do "boa" em português, não ficaria adequado, não refletiria um italiano falado corrente, uma vez que contemporaneamente é usado com mais frequência para adjetivar coisas de comer, e não lugares. Já o "nonnina", nem sempre comum, foi considerado por nós adequado no caso pois, como em português, o diminutivo é usado de forma carinhosa, o que reflete a atmosfera da frase no contexto do livro.

Também o título Mariolino e Luigino buscou manter a rima presente em Maricota e Cocota. Este livro trazia uma canção infantil com rimas que ganhou uma versão que manteve a estrutura, mas alterou alguns elementos - inserindo também aqui a temática do alimento para priorizar a rima:

Torce, retorce procuro mas não vejo. Não sei se era pulga Ou se era um percevejo.

Torce, retorce procuro mas não vejo. Não sei se era pulga ou se era um percevejo. (p. 23)

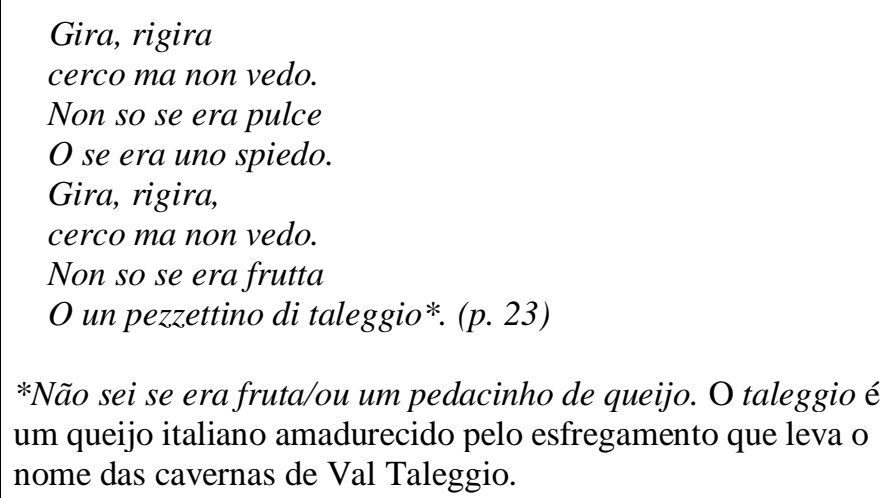


Em outras situações, o literal foi abandonado por sua inadequação. Note-se no trecho a seguir:
Enquanto a vovó varre, as crianças ajudam.
(1) Mentre la nonna scopa per terra i bambini l'aiutano.
(2) Mentre la nonna spazza per terra i bambini l'aiutano.
(3) Mentre la nonna pulisce per terra i bambini l'aiutano.

A primeira opção foi eliminada rapidamente, pois no italiano standard o verbo "scopare" pode ter uma conotação sexual. Eliminada essa ambiguidade indesejada, restou-nos escolher a melhor sonoridade e o verbo mais usual. Ficamos com a terceira opção.

Um outro caso em que manter a literalidade é quase sempre impossível é quando encontramos uma expressão idiomática ou um provérbio. Em Minha tia faz doce no tacho nos deparamos, por exemplo, com a expressão "no dia de São Nunca", que foi substituído por seu equivalente em italiano "quando gli asini voleranno" que, em português brasileiro, poderia ser traduzido por quando os burros voarem.

\section{O alimento}

Lembrando Benjamin (2002), acreditamos que, para traduzir, escrever ou ilustrar, é preciso buscar a criança que nunca nos abandonou e, consequentemente, acionar os sabores e as lembranças de nossa tenra idade. Na tradução de Minha tia faz doce no tacho, fizemos uma grande viagem entre a infância italiana de Sergio e a brasileira de Daniela e Valéria, na tentativa de resgatar também os sabores da infância dos descendentes de italianos. Destacamos a importância do alimento no texto literário como um fator que deve ser levado em consideração, já que, além de ser um forte elemento afetivo da cultura italiana, é algo recorrente em nosso cotidiano e pode funcionar como um elemento de aproximação do leitor ou de estranhamento, dependendo do objetivo que se pretenda.

Conforme as relações estabelecidas por Bunn (2011, p. 31), o ato de comer, além de necessário, é estético. Podemos observar que a presença do alimento e do ato de comer nas histórias está fortemente ligada a fatores históricos e culturais (como o tipo de alimento, os pratos típicos ou contemporâneos, os processos de industrialização, a comensalidade e mesmo a atualização e exclusão de alguns componentes) e que esses traços, aliados aos processos de fantasia e imaginação, contribuem para tornar o texto mais atrativo ao leitor. Atualmente, conforme destaca a mesma autora, em tempo de abundância alimentar, o comer fora de casa 
ganha espaço e podemos pensar em duas maneiras deste comer. Uma que se caracterizaria por uma busca pelo singular, único, tradicional - um lugar específico que tenha uma comida específica, que é um forte traço da cultura italiana, por exemplo (BUNN, 2011a). Outra que diz respeito a lugares em qualquer parte do mundo que tenham a mesma comida, uma comida padronizada, que seria o que Fischler (1990) denominou como cacofonia alimentar, conviver com o light, o fast-food, numa cultura gastro-anômica (jogo de linguagem construído pelo autor com a junção do prefixo "gastro" com o conceito durkheiniano de anomia - ausência de lei ou regra).

O livro de Messias, porém, transporta o leitor para o mundo dos sabores mineiros bem caseiros, dos cheiros e das gostosuras: a goiabada cascão, o queijo meia-cura, o doce enroladinho. Em alguns exemplos específicos, procuramos uma domesticação dos termos, no sentido de aproximar os leitores do texto. Desafios e experiências pessoais fizeram parte desta tarefa, desde a adaptação da língua portuguesa à italiana até a da cultura mineira à ítalocatarinense, onde as memórias de infância mesclaram-se com as vivências contemporâneas.

Para Georges Mounin (1975), duas condições são necessárias para a tradução, nenhuma 80 das quais é suficiente por si só: conhecer uma língua e conhecer a civilização da qual fala esta língua, ou seja, a vida, a cultura, a etnografia mais completa do povo do qual esta língua é o meio de expressão.

O tradutor, muitas vezes, terá que optar pela escolha de um ou outro termo. Por vezes, isso pode até mesmo acarretar na eliminação de uma referência cultural. Ao invés de deixar vários itens com nomes em português, procuramos em alguns casos “domesticar" os nomes dos alimentos e privilegiar doces típicos da infância italiana ou ítalo-brasileira.

Um exemplo dessa domesticação foi o termo "goiabada cascão". Como fazer com que um italiano imaginasse que esse doce de goiaba era uma "marmellata" tão bem apurada a ponto de ser cortada? Privilegiamos então justamente a consistência, mencionando a goiaba em outras passagens, mas deixando no lugar da "goiabada cascão" apenas “dolce al taglio" (doce a corte). Tínhamos em mente nosso público-alvo que teria facilmente acesso aos livros nas duas línguas, o que gerava uma certa tensão nestas escolhas, mas nossa preocupação era que o texto de nossa tradução fosse fruível também para o leitor italiano, que frente a um literal "dolce di guava" (guava=goiaba) não imaginaria como é a sobremesa "Romeu e Julieta", citada no livro (que curiosamente tem seu nome inspirado justamente em dois personagens shakespeareanos de origem italiana).

Inclui-se aqui um tópico totalmente recriado pelos tradutores: doces tipicamente 
mineiros substituídos por doces conhecidos pelos prováveis leitores e relacionados ao universo ítalo-brasileiro.

Ao final de Minha tia faz doce no tacho, há duas receitas de doces de tacho tipicamente mineiros, "Goiabada de tacho amassadinho" e "Doce de leite de vaca mansa". Tínhamos, porém, que lidar com adaptações coerentes com as imagens e ao mesmo tempo trazer à publicação italiana doces com uma certa carga afetiva para o público-alvo. Pesquisamos um pouco, discutimos outro tanto e acabamos decidindo por dois doces fáceis de fazer, o "Tiramisù", a sobremesa italiana mais popular da atualidade (com ingredientes adaptados à realidade brasileira para que se possa preparar a receita aqui), e os "Crostoli", que por sua vez são o prato mais lembrado pelos filhos, netos e bisnetos dos imigrantes, com muitas variações e nomes, bastante conhecido mesmo por quem não tem família italiana. Afinal, quem nunca comeu, mesmo sem saber que é um quitute italiano, "orelha de gato" ou "cueca virada"?

\section{O desafio de traduzir literatura infantojuvenil}

Se traduzir um texto literário já é um desafio, traduzir um texto de literatura infantojuvenil não é tão simples como aparenta. Vários são de fato, nesse caso, os níveis semióticos em jogo: a relação entre fala e imagem; a manutenção do lúdico; a questão do gênero das palavras - diferente de uma língua e cultura para outra; a proximidade com a oralidade e com o poético, a necessidade e a importância, para a legibilidade de um texto desse tipo, da rima, das assonâncias, do ritmo; a adaptação das marcas culturais do texto de partida e do texto de chegada.

Neste caso se trata de uma verdadeira reescritura como a define Lefevere (2007, p. 24):

[...] a tradução é a forma mais reconhecível de reescritura e potencialmente a mais influente por sua capacidade de projetar a imagem de um autor e/ou de uma (série de) obra(s) em outra cultura, elevando o autor e/ou as obras para além dos limites de sua cultura de origem.

Nossa tradução se fez não só no "para além” da cultura de origem, mas buscou também um "para aquém", um voltar a nossas memórias infantis e ao gosto da brincadeira e da mordida no doce para tentar oferecer ao leitor uma língua italiana assim: convidativa, gostosa, diferente e ao mesmo tempo reconhecida como algo seu. A este ponto, o processo de tradução tornou-se de fato saber com sabor, pois nos divertimos traduzindo e degustando na memória nossa infância alimentar. Numa mescla entre tradução, criação, recriação e recreação.

\section{Conclusões}


Esta breve análise do processo de criação intenso que foi a tradução desses livros tinha como objetivo enfatizar exatamente essa criação de um novo texto que seria a tradução e mostrar algumas opções concretas que ilustrassem esse trabalho autoral. De fato, de trabalho autoral se trata, ao nosso ver, quando consideramos que, como mostrado no artigo, perante as peculiaridades do texto (literatura infantojuvenil) e as diferenças, não somente linguísticas, mas, sobretudo, culturais entre os dois sistemas (o italiano e o brasileiro) foi necessário desconstruir o texto de partida e reconstituir, a partir de sua função, o mesmo conteúdo em uma outra língua e cultura. Nesse processo de mediação é inevitável, como mostramos no nosso processo, tomar decisões autorais que ressignifiquem o texto de partida para que signifique algo para o leitor de chegada. Todas essas variáveis foram meticulosamente consideradas e levaram a escolhas que proporcionassem não uma mera reprodução literal dos textos de partida, (f)ato que teria redundado em textos insignificantes para o polo de chegada. Isso é para nós tradução: um ato de criação autoral, uma transferência intersistêmica de sentido.

\section{REFERÊNCIAS}

82 ALVES, Fábio; MAGALHÃES, Célia; PAGANO, Adriana. Traduzir com autonomia. 3. ed. São Paulo: Editora Contexto, 2010.

BENJAMIN, Walter. Reflexões sobre a criança, o brinquedo e a educação. São Paulo: Editora 34, 2002.

BERGSON, Henri. O riso. São Paulo: Martins Fontes, 2001.

BUNN, Daniela. Adaptação ou estranhamento: a potência de um fragmento na tradução de literatura infantil. Cadernos de literatura em tradução, São Paulo, FFLCH/USP, v. 12, p. 103-112, 2011a.

BUNN, Daniela. A Imagem alimentar e o advento do menor na literatura infantil: estranhamentos de Gianni Rodari. 274 f. Tese (Doutorado) - Universidade Federal de Santa Catarina, Centro de Comunicação e Expressão, Programa de Pós-graduação em Literatura, Florianópolis, 2011. Disponível em: https://repositorio.ufsc.br/handle/123456789/95690. Acesso em: jun. 2019.

CALVINO, Italo. Se um narrador numa noite de inverno. In: CALVINO, Italo. Se um viajante numa noite de inverno. Traduzido por: Nilson Moulin. São Paulo: Companhia das Letras, 1990.

CAMARGO, Luis. Pra que serve um livro com ilustrações? In: JACOBY, Sissa (org.). A Produção Cultural para a Criança. Porto Alegre: Mercado Aberto, 2003.

ECO, Umberto. Dire quasi la stessa cosa, esperienze di traduzione. Milano: Bompiani, 2003. 
FISCHLER, C. L'(H)omnivore. Paris: Odile Jacob, 1990.

JAKOBSON, Roman. Linguística e Comunicação. São Paulo: Cultrix, 2005.

ISOPPO, Valéria. Veneranda e os outros ou as Alices de Veneranda. Nonsense. O avesso do senso - Revista de Divulgação Cultural, Blumenau, FURB, ano 26, n. 82, p. 78-88, jan/abr 2004

LEFEVERE, André. Tradução, reescrita e manipulação da fama literária. Traduzido por: Claudia Matos Seligmann. Bauru: Edusc, 2007.

MARTINS, Marta. Mariolino e Luigino. Ilustrações de Estela Schauffert. Traduzido por: Daniela Bunn e Sergio Romanelli. Revisão de Valéria Isoppo. Florianópolis: Cuca Fresca, 2011. $32 \mathrm{p}$.

MARTINS, Marta. Maricota e Cocota. Ilustrações de Estela Schauffert. 3. ed. Holambra: Cuca Fresca, 2009. 32 p.

MESSIAS, Adriano. Minha tia faz doce no tacho. São Paulo: Cuca Freca, 2012.

MOUNIN, Georges. Problemas teóricos da tradução. Traduzido por: Heloisa de Lima Dantas, São Paulo. Cultrix, 1975.

QUEIROZ, Magali. Casa de vó é gostoso que só! Ilustrações de Vera Muccillo.

Florianópolis: Cuca Fresca, 2010. 24 p.

QUEIROZ, Magali. La casa della nonnina è troppo carina! Ilustrações de Vera Muccillo. Traduzido por: Daniela Bunn e Valeria Isoppo. Revisão de Sergio Romanelli. Florianópolis: Cuca Fresca, 2011. 24 p.

MUNDT, Renata. A adaptação na tradução de literatura infanto-juvenil: necessidade ou manipulação? In: Anais do XI Congresso Internacional da ABRALIC. Disponível em: http://www.abralic.org.br/eventos/cong2008/AnaisOnline/simposios/pdf/073/RENATA_MUN DT.pdf. Acesso em: 26 set. 2010. p. 1-10.

ROMANELLI, Sergio. Processo criativo e Tradução. In-traduções. Revista do Programa de Pós-graduação em Estudos da Tradução da UFSC. Florianópolis: PGET, v. 2, n. 2, 2010.

ROSENWEIG, Franz. "Scripture and Luther". In: BUBER, Martin; ROSENZWEIG, Franz. Scripture and translation. Traduzido por: Lawrence Rosenwald, Everett Fox. Bloomington: Indiana University Press, 1994. p. 47-69.

\footnotetext{
* Daniela BUNN - Doutora em Literatura (2011) pela Universidade Federal de Santa Catarina. Mestre em Literatura (2004) pela Universidade Federal de Santa Catarina (UFSC). Graduada em Letras Português/Italiano (2001) pela Universidade Federal de Santa Catarina (UFSC). Atualmente é professora do Centro de Educação da Universidade Federal de Santa Catarina, vinculada ao Departamento de Metodologia de Ensino e atua no curso de Letras Italiano. Florianópolis, Santa Catarina, Brasil. Currículo acadêmico: http://lattes.cnpq.br/6305973758863545

ORCID: https://orcid.org/0000-0002-3072-7599
} 
E-mail: daniela.bunn@ufsc.br

** Sergio ROMANELLI - Doutor (2006) e Mestre (2003) em Letras e Linguística pela Universidade Federal da Bahia. Graduado em Lettere e Filosofia (1997) pela Universita Degli Studi di Milano, Italia. Realizou estágio de pósdoutorado na Antwerp University, Bélgica (2013-2014). Professor associado I na Universidade Federal de Santa Catarina. Bolsista de Produtividade em Pesquisa do CNPq - Nível 2. Florianópolis, Santa Catarina, Brasil.

Currículo acadêmico: http://lattes.cnpq.br/5423619978562049

ORCID: https://orcid.org/0000-0002-4487-4207

E-mail: sergioroma70@ gmail.com

${ }^{* * * *}$ Valeria ISOPPO - Mestre em Teoria Literária (2010) pela Universidade Federal de Santa Catarina. Graduada em Letras Português/Italiano (2001) pela mesma instituição. Atua como tradutora juramentada de italiano. Florianópolis, Santa Catarina, Brasil.

Currículo acadêmico: http://lattes.cnpq.br/1797195274700339

ORCID:

E-mail: valeriaisoppo@ hotmail.com 